\title{
The rate of pregnancy in Trinidad and Tobago: A comparison between pregnant teenagers and pregnant adults registered at three health centers
}

$\frac{1}{1}$
$\frac{\pi}{2}$
$\frac{\pi}{4}$
$\frac{\pi}{4}$

Joan M. Rawlins, Isaac Dialsingh', Tazhmoye V. Crawford', Samantha G. Rawlins ${ }^{3}$, Donovan A. McGrowder ${ }^{4}$

Departments of Paraclinical Sciences, Public Health and Primary Care Unit, Faculty of Medical Sciences, ${ }^{1}$ Mathematics and Statistics, University of the West Indies, St. Augustine, Trinidad and Tobago, ${ }^{2}$ Independent Health

Policy Consultant, Christiana,

Manchester, UK, ${ }^{3}$ Advanced Ob/Gyn Associates, 256 Columbia Turnpike \#212N Florham Park, NJ,

USA, ${ }^{4}$ Department of Pathology,

University of the West Indies,

Mona, Kingston, Jamaica

Address for the Correspondence:

Dr. Joan M. Rawlins, Department of Paraclinical Sciences, Unit of Public Health and Primary Care, University of the West Indies, Eric Williams

Medical Sciences Complex Champs Fleurs, St. Augustine, Trinidad and Tobago, West Indies.

E-mail: rawlinsjm@yahoo.com

\begin{tabular}{|l|}
\hline Access this article online \\
\hline Website: www.ijmedph.org \\
\hline DOI: 10.4103/2230-8598.118942 \\
\hline Quick response code: \\
\hline
\end{tabular}

\begin{abstract}
Aim: This paper aims to determine the difference between the health and social conditions of women who had their first pregnancy as teenagers (13-19 years old) and those who had their first pregnancy during post-adolescence (20-41 years old). Materials and Methods: The results were based on a structured, 60-item interview schedule with 132 cases (71 teenagers and 61 women $\geq 20$ year old) in Trinidad and Tobago. These cases comprised Afro-Trinidadians, Indo-Trinidadians, and Trinidadians of "Mixed" ancestry, who were all recruited by nurses in three health centers in Northern Trinidad, during the period October 2004 to October 2005. The main issues of concern regarding the respondents were history of stillbirths, abortion, contraceptive use, intended family size, marital status, and employment status. Data were analyzed, using Statistical Package for the Social Sciences (SPSS) 12.0. Results: While the study shows similarity between the two groups of respondents, in terms of their breast-feeding practices, there were differences regarding teenage mothers who experienced a higher level of unemployment ( $35 \%)$, single and common law relationships $(81 \%)$, and lower contraceptive use $(11.8 \%)$. The older mothers were more likely to be classified as unskilled (34.4\%) compared to $22.5 \%$ for the teen group. Conclusions: The findings reveal that teenage pregnancy is considered a risk factor and has socio-economic implications regarding the lives of the mother and child in terms health, income, employment, and marital status.
\end{abstract}

Key words: Adults, social, teenage, pregnancy, Trinidad

\section{INTRODUCTION}

This paper addresses the issue of pregnancy among teenagers 13-19 years old and women 20-41 years old (herein referred to as the older mother) living on the twin Island of Trinidad and Tobago. This country is situated at the Southern end of the Caribbean-Northeast of Venezuela; measures 5,128 square kilometers and comprises a population of 1,229,953, whereby teenagers represent approximately $22 \% .^{[1]}$ The issue of teenage pregnancy worldwide is viewed as a major social and medical problem. ${ }^{[2]}$ Studies have shown that teenage mothers are more likely to suffer many adverse medical outcomes, both during and after pregnancy. ${ }^{[3]}$ These outcomes include hypertensive disorders, ${ }^{[4,5]}$ anemia, ${ }^{[5]}$ cephalopelvic disproportion, ${ }^{[6]}$ increased rate of caesarian sections, ${ }^{[4]}$ and postpartum depression. ${ }^{[7]}$ The literature also noted that not only are pregnant teenage girls at risk for their own health, but that the unborn child is at increased risk of prematurity, ${ }^{[4]}$ low birth weight, ${ }^{[8]}$ congenital malformations, ${ }^{[9]}$ increased risk of neonatal deaths, ${ }^{[10]}$ and death during infancy. ${ }^{[1]}$

In Trinidad and Tobago, teenage pregnancy continues to be a significant social and health concern. Data from the Central Statistical Office (CSO) Trinidad and Tobago informs that there has been no significant decline in the number of teenage pregnancies in the population in the last decade. According to the CSO, teenage girls gave birth to 2,638 children in 2000, representing $15 \%$ of all live births in Trinidad and Tobago. ${ }^{[12]}$ The various concerns arising from teenage pregnancy are neither new nor unique to the Caribbean region. Rawlins $(1981 ; 1984)$ argues that parents and health officials were already concerned with what they saw as the "problem" of teenage pregnancy in the Caribbean. ${ }^{[13]}$ Some scholars (particularly in the 1970s) viewed teenage pregnancy as a potential population problem, considering that early pregnancies increase the chances of larger family size. In 
those days, teenage pregnancy contributed 30\% birth for countries such as St. Kitts and Nevis, Dominica and St. Lucia and 32\% for Jamaica (Rawlins 1981). ${ }^{[13]}$ Such concerns within the Caribbean deem teenage pregnancy a problem owing to its association with disrupted educational opportunities, high incidence of interrupted pregnancies, early sexual activity, and exposure to sexually transmitted infections (STIs) including human immunodeficiency virus (HIV). The Caribbean Epidemiology Centre (CAREC) showed that the fastest growing rate for HIV / AIDS was within the 15-19 age group, which were said to be five times more likely to be infected than their age mates. ${ }^{[14]}$ It follows that teenagers, who become pregnant are exposing themselves to the risk of serious health consequences.

On the point of interrupted pregnancies, noted above, such statement is supported by Abdool et al., (2002), who claimed that the typical patient who abused misoprostol as an abortifacient, is usually young single women. ${ }^{[15]}$ This sometimes result in hospitalization of the patient for approximately two days. The average cost for treatment and care of this nature within the health care facility is approximately TT $\$ 2,282$ (US \$380) in 2007. This paper addresses the social-economic status of the pregnant teenagers in Trinidad and Tobago, as well as their past obstetric history in relation to abortions and still births; their use of contraceptives and the matter of breastfeeding practice. Further, the paper compares the women who were teenagers at the time of first pregnancy, as against those who reported their first pregnancy during post-adolescence (ages of 20-41).

\section{MATERIALS AND METHODS}

This study utilizes mixed method approaches: Primary and secondary. The former represents collecting data directly from respondents who attended antenatal clinics at three different locations in Trinidad and Tobago, while the latter involves information obtained from desk review. Pregnant women in the third trimester of pregnancy were recruited by nurses in three Health Centers in Northern Trinidad. The sample size comprised 132 women (ages 13-41 years old), who were interviewed by medical students of the University of the West Indies, Mount Hope, St. Augustine Campus, in Trinidad and Tobago. These students were professionally trained to conduct such interviews. Consent forms were signed by the respondents prior to the interviews. The interviewees were given the option to opt-out should they become uncomfortable with any of the questions asked.

The instrument was a 60-item interview schedule. Data collected included demographic information, the respondents' financial status, obstetric history, their preferred contraceptive method(s), and breast feeding practice.

Data were analyzed using Statistical Package for the Social Sciences (SPSS) 12.0. Two control groups were established: (1) Those who had their first pregnancy while in their teenage years (13-19 years old) and (2) those who experienced their first pregnancy during their post-adolescence/adulthood (20-41 years old).

\section{RESULTS}

\section{First pregnancy per age category}

The data obtained from three Health Centers in Northern Trinidad and Tobago represents cases by categories of women who had their first pregnancy as teenagers (13-19 years old), as well as adults within the age group of 20-41 years. The sample comprised 132 women within the 13-41 years age category. A significant percentage (53\%) of this sample experienced their first pregnancy before the age of 20 years. The youngest age reported for first pregnancy was 13 years. Most of the older women had their first pregnancy between the ages 20-24 years.

\section{Ethnicity}

Table 1 gives a breakdown of the age at first pregnancy by ethnicity. It is revealed that the Afro-Trinidadians were the most likely to become teenage mothers (48.6\%), followed by those who were Mixed (31.4\%) and Indo-Trinidadians (20\%). The respondents who were categorized as the older women (20-41) were not significantly different in terms of those of their racial status: Bi-racial $(31.4 \%)$, Indo-Trinidadians (21.3\%), and Afro-Trinidadians (42.6\%).

\section{Marital status}

The marital status of the respondents were assessed, and it was noted that of the 71 respondents who had their first pregnancy as teenagers, $38.0 \%$ reported to be single; $43.0 \%$ engaged in common-law relationship, and $18.3 \%$ were married. In terms of the post-adolescent/older respondents, $37.7 \%$ reported being married, $36.1 \%$ single, while $26.2 \%$ engaged in common-law relationship [Table 1].

\section{Employment and income status}

Although, there is no significant difference in the reported cases of marital status versus employment, the findings reveal that teenage mothers $(35.2 \%)$ were more likely to be unemployed than the older mothers $(23.0 \%)$. On the contrary, although the teenage mothers $(22.5 \%)$ were less susceptible to being unskilled compared

\begin{tabular}{lcc}
\multicolumn{3}{l}{ Table 1: Demographic characteristics } \\
\hline Variables & $\begin{array}{c}\text { Teen } \\
\text { mother (\%) }\end{array}$ & $\begin{array}{c}\text { Post-adolescent/ } \\
\text { older mother (\%) }\end{array}$ \\
\hline Ethnicity & & \\
$\quad$ Afro-Trinidadians & 48.6 & 42.6 \\
Indo-Trinidadians & 20.0 & 21.3 \\
$\quad$ Bi-racials/mixed & 31.4 & 31.4 \\
Marital status & & \\
$\quad$ Single & 38.0 & 36.1 \\
Common law & 43.0 & 26.2 \\
$\quad$ Married & 18.3 & 37.7 \\
Employment status & & \\
$\quad$ Unemployed & 35.2 & 23.0 \\
Unskilled & 22.5 & 34.4 \\
Skilled & 21.1 & 23.0 \\
Homemaker & 21.1 & 19.7 \\
\hline
\end{tabular}


to the older mothers $(34.4 \%)$, they were more likely to become homemakers/housewives $(21.1 \%)$ than the older mothers $(19.7 \%)$.

Where income was concerned, the teenager mothers reported lower income than the older mothers. The income for the teenagers ranged from TT $\$ 700$ to 4500 per month (TT\$ 6.00 is approximately US\$1.00), whereby $36.4 \%$ earned $\$ 700-2000$ and $45.5 \%$ reported earnings of TT $\$ 2001-\mathrm{T} T \$ 4500$ per month. For the older mothers, $50 \%$ reported family income in excess of TT $\$ 4,500$ per month, with 37\% earning between TT\$2,000-TT\$ 4,500 per month.

\section{Obstetric history}

A particular concern of this study was the obstetric history of the mothers in relation to breast-feeding practice, live births, stillbirths, abortion, and contraceptive use. Breast-feeding is practiced more among the older woman $(95.5 \%)$ than the teenage mother $(90.7 \%)$, as indicated in Table 2. Of the 71 respondents who reported having had at least one previous live birth, 85.9\% represents teenage mothers. The average number of children for the teenage and older mothers represents $1.4 \%$ and $1.4 \%$, respectively. Fewer teenage mothers $(3.3 \%)$ experienced stillbirths than the post-adolescent/older mother (8.2\%) [Table 2].

Regarding the number of abortions experienced, this study postulates that the older mothers were more likely to have two or more abortions than the teenage mothers, who were more likely to have one abortion. While $50.0 \%$ of teenage mothers had never experienced an abortion, $38.0 \%$ of the older mothers fell within this category [Table 2].

Table 2 shows the outcome of the last pregnancy and notes that there was no statistical difference in relation to induced abortion between the teenagers and older mothers $\left(\chi^{2}=0.83, P=0.01\right)$.

\section{Contraceptive prevalence}

With regard to the issue of contraceptive use prior to first pregnancy, Table 2 shows that $28.0 \%$ of the teenage mothers and $51.0 \%$ of

\begin{tabular}{lcc}
$\begin{array}{l}\text { Table 2: Sexual and reproductive health } \\
\text { characteristics }\end{array}$ & $\begin{array}{l}\text { Teen } \\
\text { mother (\%) }\end{array}$ & $\begin{array}{c}\text { Post-adolescent/ } \\
\text { older mother (\%) }\end{array}$ \\
\hline Variables & & \\
& 90.7 & 95.5 \\
\hline Obstetric history & 1.4 & 1.4 \\
Practice breastfeeding regularly & 3.3 & 8.2 \\
Live births (children late died) & 50.0 & 38.0 \\
Stillbirth & 61.0 & 69.0 \\
Never committed an abortion & 38.0 & 32.0 \\
Desirous of having 1-2 children & & \\
Desirous of bearing 3-5 children & 28.0 & 51.0 \\
Contraceptive prevalence & 47.0 & 62.5 \\
General contraceptive use & 11.8 & 12.5 \\
Pills & 23.5 & 12.5 \\
Other methods & 17.6 & 12.5 \\
Condom & & \\
Dual methods &
\end{tabular}

the older mothers reported contraceptive use. Consonant with this finding, this Table also reveals that the older mothers were more likely to use the pill $(62.5 \%)$ and other methods $(12.5 \%)$ when compared to the teenage mothers $(47.0 \%$ and $11.8 \%$, respectively). However, the use of condom and dual methods ranked higher among teenage mothers $(23.5 \%$ and $17.6 \%$, respectively) than the older mothers $(12.5 \%$ and $12.5 \%$, respectively).

\section{Intended family size}

Table 2 reveals that there was no significant difference between teenage mothers who wanted to have one or two children $(61.0 \%)$ and the older mothers $(69.0 \%)$ who desired same. There was also no significant difference between the teenage mothers who were desirous of having three to five children $(38.0 \%)$ and the older mothers $(32.0 \%)$ who shared a similar view point.

\section{DISCUSSION}

Age at first sexual debut among Caribbean teens is not unusual before the age of 15 years. In countries such as Antigua and Barbuda, Haiti, Jamaica, Guyana, Trinidad and Tobago and the Dominican Republic, one in six females between the ages of 15 and 24 years become sexually active before the age of 15 . A 2000 survey conducted by the Pan American Health Organization (PAHO) revealed that nearly half of all young girls reported that their first sexual encounter was forced or coerced. ${ }^{[16]}$

In view of Trinidad and Tobago's unemployment rate of $5.2 \%$, the paper reveals that teenage mothers $(35.2 \%)$ were more likely to be unemployed than older women $(23 \%)$. This evidence is supported by (Buvinic 1998), who intimated that adolescent motherhood was associated with poor earning opportunities for the teenager, necessitating the frequent occurrence of grandparents having to take over responsibility for child care. ${ }^{[17]}$ Consonant with this perspective, Grogger and Bronars (1993) stated that the there are correlations between teenage pregnancy and lower family earning (including household income). ${ }^{[18]}$ In supporting the views of the authors, the findings of this paper also reveal that a large percentage of the teenage mothers were unemployed $(35 \%)$ and for those who were employed (36.4\%), earned less than TT\$2,000 (less than US\$ 350) per month. This stands to reason that the teenage mother is likely to be socially disadvantaged, with higher unemployment level, lower incomes, and a marital status which has limited or no security. Such insecurity, as well as low income and unemployment, often lead to teenagers forming intimate relationships with older men. This usually led to further pregnancies and income dependency. Daguerre and Nativel (2006) hypothesized that minimal safety net is likely to incur higher rates and births to teenagers and that the use of contraception is dependent on low educational outcomes. ${ }^{[19]}$ This is not unique to Trinidad and Tobago, as adolescent or teenage sexual activity and pregnancy in Jamaica, ${ }^{[20]}$ Guatamala, ${ }^{[21]}$ and Latin America ${ }^{[22]}$ have been thought to be associated with poverty, poor education, among other social factors. 
In a number of cases, the insecurity of the relationships, as well as dependence on income, causes the teenage and older mothers to not be able to negotiate safe sexual practice via contraceptive method. Research has shown that unmarried young women, who face additional barriers to obtaining contraceptives, including social disapproval of contraceptive use, are less likely to use contraception than young married women. ${ }^{[23]}$ In the case of Jamaica such barriers include (a) adolescent male gaining more favorable access to contraceptive service and treatment than their female counterpart; and (b) the female is categorized as bad and wanton when trying to access contraceptive methods, while masculinity of the male is being promoted. ${ }^{[24]}$ The study also revealed that there was a relationship between male and female who encounter challenges in accessing contraceptive.

There was no correlation between the mother's age range and breastfeeding, as other relating factors would be considered. This lifestyle was practiced more among the older woman than the teenage mother. In comparing breastfeeding patterns in Africa (AFR) and the Latin American and Caribbean region (LATCAR) based on demographic and health, in surveys conducted in 23 countries between 1986 and 1990, the proportion of infants who are never breastfed is twice as high in LATCAR than in AFR. The average median breastfeeding duration is 1.64 times higher in AFR (193.0 months) than in LATCAR (11.8 months). The longer breastfeeding duration found in AFR was due to a better lactation performance in both rural and urban areas. In both LATCAR and AFR, $71 \%$ of the $0-4$-month infants were not breastfed exclusively during the first 4 months of life and breastfeeding duration was longer in rural than in urban areas. However, the degree of urbanization had a stronger negative effect on breastfeeding in LATCAR than in AFR. It is, therefore, concluded that (a) while LATCAR is in great need of breastfeeding promotion programs, breastfeeding in AFR should be protected as it becomes more urbanized; (b) the promotion of exclusive breastfeeding remains a priority in both regions; and (c) the magnitude of the inverse association between urbanization and breastfeeding is likely to vary among regions with different socio-economic and cultural backgrounds. ${ }^{[25]}$

Coupled with the foregoing, the intense review of the literature notes that studies have shown that teenage pregnancy is considered a poor choice on both health and social grounds. Teenage parents tend to have poor antenatal health, lower birth weight babies, higher infant mortality rates, and an increased risk of congenital anomalies. While they are likely to seek antenatal care much later in pregnancy than older women, teenage mothers miss out on important and early pregnancy health measures, such as taking folic acid. Teenage mothers are also less likely to breastfeed their babies than older mothers and are more likely, if from a deprived background, to remain poor and to experience higher levels of unemployment. They are also disproportionately likely to suffer relationship breakdown. However, for some young women, having a baby is seen as a positive step, one that offers a sense of purpose in a life that might have few other options. It is towards this group of women that teenage pregnancy teams are directing their greatest efforts. ${ }^{[2]}$

While the literature points to many concerns about health risk for the outcomes of teenage pregnancy, it should be noted that the findings of this study reveals that stillbirths among teenage mothers represents $3.3 \%$ and the older mother, $8.8 \%$, and complements the overall concern of stillbirths in Trinidad and Tobago. Physicians in this island often postulate that this was as a result of failure of the pregnant woman to attend antenatal clinics. ${ }^{[12]}$

Another health issue that is being presented in this study is the matter of interrupted pregnancy or abortion. It is noted that teenage mothers who experience spontaneous abortions represented $64.3 \%$ and $60 \%$ of the induced abortions. This suggests that pregnant teenagers had a larger percentage of pregnancies which had been interrupted.

\section{CONCLUSION}

Teenage pregnancy is considered a risk factor and has socio-economic implications regarding the lives of the mother and child in terms health, income, employment, and marital status. Pregnancy of the teenager and older mother bears no association with ethnicity. Despite employment and marital status, the pregnant woman (both categories) become vulnerable owing to insecurity (single and unemployed), hence their inability to negotiate condom use. This paper assumes that owing to the respondents' exposure to antenatal treatment, this result in a small number of the subjects experiencing stillbirths.

\section{ACKNOWLEDGMENTS}

We wish to thank the nurses of the three health Centers, especially Nurse Marilyn Martin of the Arima Health Center, who facilitated the interviews of the respondents. Thanks also to Ms. Abena Thomas for her research assistance.

\section{REFERENCES}

1. Central Intelligence Agency. The World Fact Book. Trinidad and Tobago. 2009. Available from: https://www.cia.gov/library/publications/ the-world-factbook/geos/td.html [Last accessed on 2012 May 5].

2. Dickson R, Fullerton D, Eastwood A, Sheldon T, Sharp F. Preventing and reducing the adverse effects of unintended teenage pregnancies. Effect Health Care Bull 1997;3:1-10.

3. Cunnigton $A$. What is so bad about teenage pregnancy? J Fam Plann Reprod Health Care 2001;27:36-41.

4. Scholl TO, Hediger ML, Belsky DH. Prenatal care and maternal health during adolescent pregnancy: A review and meta-analysis. J Adolesc Health 1994;15;444-56.

5. Konje JC, Palmer A, Watson A, Hay DM, Imrie A, Ewings P. Early teenage pregnancy in Hull. Br J Obstet Gynaecol 1992;99:969-73.

6. Savona-Ventura C, Grech ES. Multiple pregnancy in the Maltese population. Int J Gynaecol Obstet 1988;26:41-50.

7. Maskey S. Teenage pregnancy: Doubts, uncertainties and psychiatric disturbance. J R Soc Med 1991;84:723-5.

8. Fraser AM, Brockert JE, Ward RH. Association of young maternal age with adverse reproductive outcomes. N Engl J Med 1995;332:1113-7.

9. Grazi RV, Redhenndran R, Mudialar N, Bannerman RM. Offspring of 
teenage mothers: Congenital malformations, low birth weight and other findings. J Reprod Med 1982;27:89-96.

10. Cooper LG, Leland NL, Alexander G. Effect of maternal age on birth outcomes among young adolescents. Soc Biol 1995;42:22-35.

11. Guyer B, MacDorman MF, Martin JA, Peters KD, Strobino DM. Annual summary of vital statistics-1997. Pediatrics 1998;102:1333-49.

12. Stillbirths worrying officials- pre-natal care a must. Sunday Guardian, Trinidad; 2006.

13. Rawlins J. Parent-child interaction and teenage pregnancy. MSc. Thesis: University of the West Indies; 1981.

14. The Caribbean Epidemiology Centre and the Pan American Organization. Status and trends: Analysis of the Caribbean HIVIAIDS epidemic 1982-2002; 2004

15. Abdool MA, Bharath C, Callender A, Gopaul A, Karim K, Lacaille S, et al. Descriptive analysis of the use of misoprostol and the estimated impact on the public health care system. West Indian Med J 2002;51:17. (I agree with the et al. after listing 6 authors).

16. Pan American Health Organization (PAHO)/World Association of Sexology (WAS). Promotion of Sexual Health: Recommendation for Action. Washington, DC; 2000.

17. Buvinic M. The cost of adolescent childbearing: Evidence from Chile, Barbados, Guatemala and Mexico. Stud Fam Plann 1998;29:201-9.

18. Grogger J, Bronars S. The socioeconomic consequences of teenage childbearing: Findings from a natural experiment. Fam Plann Perspect 1993;25:156-61, 174

19. Daguerre A, Nativel C. When children become parents. UK: Policy Press; 2006.

20. Eggleston E, Jackson J, Hardee K. Sexual attitudes and behaviour among young adolescents in Jamaica. Int Fam Plann Perspect 1999;25:78-84.

21. Alan Gunmacher Institute. Women and Reproductive Health in Latin America and the Caribbean [Women, Families and the Future]. New York, NY: The Institute; 1994.

22. Martin CT. Guatemala: Encuesta Nacional de Salud Materno Infantil, 1995. [Demographic and Health survey]. Guatemala City, Guatemala Instituto Nacional de Estadistica; Calverton, MD: Macro International; 1996.

23. Population Report. Young Adults and Contraceptive Use. vol 23, Number 3, October 1995. Available from: http://www.infoforhealth.org/pr/j41/ j41chap1_6.shtml\#top [Last accessed on 2012 May 5].

24. Crawford T, Gardner M, McGrowder D, Gordon L. Socio-economics and child-bearing characteristics of young adults in Jamaica. Eur J Sci Res 2007;18:680-8

25. Perez-Escamilla R. Breastfeeding in Africa and the Latin American and Caribbean Region: The potential role of urbanization. J Trop Pediatr 1994;40:137-43.

26. Measures C. Teenage pregnancy: Mothers tide. Health Service Journal, 2009:16. Available from: http://www.hsj.co.uk/insideknowledge/ features/2009/03/teenage_pregnancy_mothers_tide.html [Last accessed on 2012 May 5].

How to cite this article: Rawlins JM, Dialsingh I, Crawford TV, Rawlins SG, McGrowder DA. The rate of pregnancy in Trinidad and Tobago: A comparison between pregnant teenagers and pregnant adults registered at three health centers. Int J Med Public Health 2013;3:129-33.

Source of Support: Nil, Conflict of Interest: None declared. 